\title{
Saliva aldosterone concentration in healthy infants
}

\author{
J D FEW, T K MANGAT, T E OPPE, AND V H T JAMES \\ Departments of Chemical Pathology and Pediatrics, St Mary's Hospital Medical School, London
}

SUMMARY Aldosterone and glucocorticoid (cortisol+cortisone) concentrations were measured in 106 saliva samples from healthy infants. Most aldosterone values fell within the adult range $(0-0 \cdot 15 \mathrm{nmol} / \mathrm{l}(0-5 \cdot 4 \mu \mathrm{g} / 100 \mathrm{ml}))$, but 10 were $>0.2 \mathrm{nmol} / \mathrm{l}(7 \cdot 2 \mu \mathrm{g} / 100 \mathrm{ml})$. Aldosterone concentration was not related to sex, ethnic origin, time of collection, distress, or cortisol concentration but decreased with age.

Plasma aldosterone concentration has often been reported to be much higher during infancy than in older children and adults. ${ }^{1-3}$ Most investigators have obtained their blood samples when infants were being bled for necessary clinical investigations. These infants, therefore, may not be representative of their age range.

Saliva is a readily accessible body fluid, the collection of which raises no ethical problems even in healthy infants. In adults the concentration of aldosterone in saliva has been shown to correlate with that in plasma ${ }^{45}$ and to approximate to the concentration of the free (non-protein bound) fraction in plasma. ${ }^{6}$ It therefore seemed appropriate to investigate the use of saliva in the assessment of aldosterone state in healthy infants.

\section{Methods}

All the subjects of this study were apparently healthy infants (aged 1-12 months) attending child health clinics. The study was approved by the local ethical committee, and consent was obtained from all the mothers. Saliva was aspirated using a plastic pasteur pipette while the infant was in the mother's arms. No stimulant was used to increase the rate of saliva flow. The age, sex, and ethnic origin of each infant was recorded, and they were categorised (after consultation with the mother) as 'calm' or 'agitated'. Some samples were collected at morning clinics (0930-1200h), but most were collected at afternoon clinics (1400-1600h). Most infants were white, but small numbers of Afro-Caribbean (11), Indian (nine), Japanese (five), and middle eastern infants (three), were included.

Aldosterone concentration was measured by a slight modification of our published method. ${ }^{5}$ The sample volume was reduced from $500 \mu \mathrm{l}$ to $100 \mu \mathrm{l}$ (in duplicate), and the final antibody dilution was altered to 1:1200 000. The limit of detection $(95 \%$ confidence) was $0.006 \mathrm{nmol} / \mathrm{l}$ $(0 \cdot 2 \mu \mathrm{g} / 100 \mathrm{ml})$, and the within and between batch coefficients of variation were $6-8 \%$ and $10 \%$, respectively.

Glucocorticoid concentration was measured by radioimmunoassay using an antibody raised against cortisol-3-CMO conjugated to bovine serum albumin (which cross reacts about $90 \%$ with cortisone), with $\left[1,2,6,7-{ }^{3} \mathrm{H}\right]$ cortisol as ligand and dextran-charcoal to separate free and bound fractions.

Table Mean saliva aldosterone and glucocorticoid concentrations in 106 saliva samples from healthy infants

\begin{tabular}{|c|c|c|c|c|c|}
\hline & \multicolumn{3}{|c|}{$\begin{array}{l}\text { Aldosterone } \\
\text { (nmol/l) }\end{array}$} & \multicolumn{2}{|c|}{$\begin{array}{l}\text { Glucocorticoid } \\
\text { (nmol/l) }\end{array}$} \\
\hline & $n$ & Mean & Range & Mean & Range \\
\hline All Infants & 106 & 0.106 & $<(1) \cdot(0)-1) \cdot 61$ & 22 & $3->110$ \\
\hline Boys & 57 & $0.1 \times 92$ & $<() \cdot(0)-1) \cdot 3.3$ & 24 & $5->110$ \\
\hline Girls & 49 & 0.089 & $(0.01-(1) \cdot 61$ & 20 & $3-59$ \\
\hline \multicolumn{6}{|l|}{ Samples: } \\
\hline Morning & 15 & 0.086 & $(0.01-0.25$ & 29 & $8-99$ \\
\hline Afternocon & 91 & 0.1109 & $<(1 \cdot(0)-() \cdot 61$ & 21 & $3->110$ \\
\hline \multicolumn{6}{|l|}{ Infants: } \\
\hline Afro-Caribbean & 11 & $0 \cdot(174$ & $0 \cdot(01-(0) \cdot 23$ & 22 & $3-99$ \\
\hline Indian & 9 & 0.167 & $(0.015-() .47$ & 39 & $10-110$ \\
\hline Whitc & 78 & 0.077 & $<(0 \cdot() 1-(1) \cdot 61$ & 19 & $8-49$ \\
\hline \multirow{2}{*}{ 'Agitated' } & $\int 5$ & 0.1095 & $0.018-1) \cdot 23$ & & \\
\hline & $\left\{7^{*}\right.$ & & & 21 & $5-50$ \\
\hline
\end{tabular}

Includes two infants from whom insufficient saliva was obtained for the aldosterone assay.

Conversion: SI to traditional units-Aldosterone: I $\mathrm{nmol} / \mathrm{l} \approx 36 \mu \mathrm{g} / \mathrm{I}(\mathrm{X} / \mathrm{ml}$ 


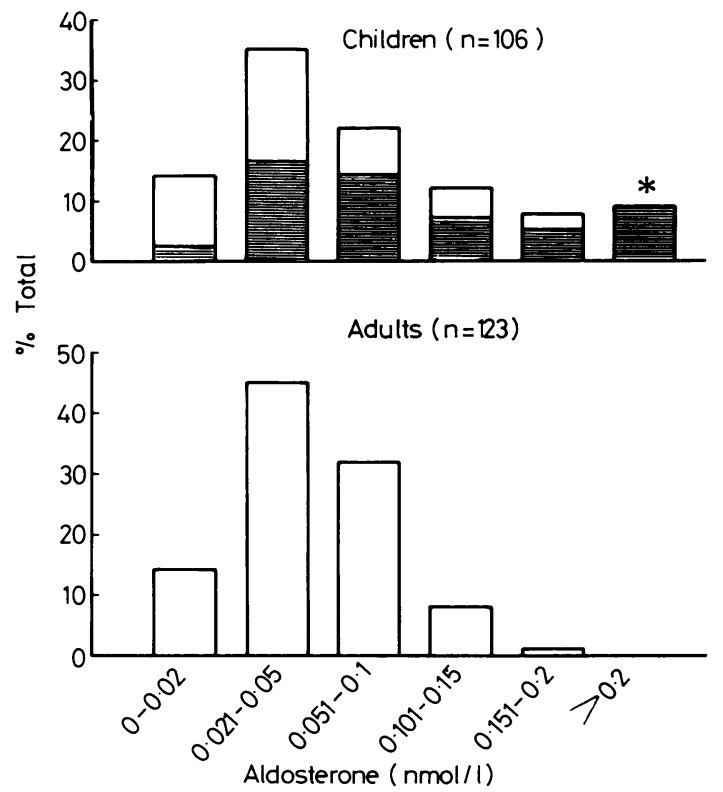

Figure Distribution of saliva aldosterone concentrations in infants and adults. Shaded areas represent children aged under 6 months.

*Mean (SD) $=(0.33(0 \cdot 1.3) \mathrm{nmol} / \mathrm{l}(11.9(4 \cdot 7) \mu \mathrm{g} / \mathrm{l}(0) \mathrm{ml})$.

Conversion: S/ to traditional units-Aldosterone: $1 \mathrm{nmol} / \mathrm{l} \approx 36 \mu \mathrm{g} / 10(\mathrm{~mL}$.

\section{Results}

The overall findings are summarised in the Table. Neither sex, time of sampling, state of arousal, nor ethnic origin were important determinants of saliva aldosterone concentration. The higher mean aldosterone for the Indian infants was due to the inclusion of two with very high values. The Figure shows that there is considerable overlap in the distribution of saliva aldosterone values in infants and adults. Infants whose aldosterone concentration is outside (above) the adult range are predominantly under 6 months of age. Aldosterone concentration did not correlate with glucocorticoid concentration either in the group as a whole $(r=0 \cdot 21)$ or in the 10 infants with very high aldosterone concentrations $(r=0 \cdot 19)$.

\section{Discussion}

This work adds to previous investigations of aldosterone state in infants. All our infants were healthy and did not justify blood sampling and so differ from those included in the majority of previous investigations. Most of the aldosterone and glucocorticoid concentrations were compatible with our adult ranges. We did observe a downward shift in the distribution of aldosterone (but not glucocorticoid) concentrations with age and found a minority of infants had aldosterone concentrations considerably above the adult range. This latter finding is unlikely to be the non-specific effect of stress as the glucocorticoid concentrations in these infants were normal. The high aldosterone concentrations found in some infants were not associated with any of the other factors recorded.

Further work is therefore needed to explain the cause of the high saliva aldosterone concentrations found in about $10 \%$ of the infants and of the decline in aldosterone concentration during the first year of life.

\section{References}

1 Kowarski A, Katz H, Migeon CJ. Plasma aldosterone concentration in normal subjects from infancy to adulthood. $J$ Clin Endocrinol Metab 1974:38:489-91.

2 Dillon MJ, Ryness JM. Plasma renin acitivity aldosterone concentration in children. Br Med J 1975;iv:316-9.

${ }^{3}$ Fiselier T, Monnens L, Van Munster P, Jansen M. Peer P, Lijnen $P$. The renin-angiotensin-aldosterone system in infancy and childhood in basal conditions and after stimulation. Eur $J$ Pediatr 1984;143:18-24.

4 McVic R, Levine LS, New MI. The biologic significance of the aldosterone concentration in saliva. Pediatr Res 1979;13:755-9.

5 Few JD. Chaudry S, James VHT. The direct determination of aldosterone in human saliva. J Steroid Biochem 1984;21:87-92.

${ }^{6}$ Few JD, Wallis PJW, James VHT. The relationship between saliva aldosterone and plasma free aldosterone concentrations. Clin Endocrinol (Oxf) 1986,24:119-26.

Correspondence to $\mathrm{Mr} \mathrm{J} \mathrm{D}$ Few, Department of Chemical Pathology, St Mary's Hospital Medical School, London W2 1PG, England.

Received 20 January 1986 